\title{
The clinical appearance of neonatal rotavirus infection: Association with necrotising enterocolitis
}

\author{
François P R de Villiers, Marie Driessen
}

Background. Rotavirus is the most important aetiological agent causing severe gastroenteritis in children $<2$ years of age in South Africa and worldwide. Most endemic neonatal nursery strains are thought to be asymptomatic. However, serious conditions have been reported to be associated with rotavirus infection, such as necrotising enterocolitis (NEC), diffuse intravascular coagulopathy, pneumonia, apnoea and seizures.

Methods. We studied newborns needing screening for sepsis in our Neonatal Unit. Rotavirus screening was included in the septic screen. The clinical signs and symptoms were studied in the control group (no rotavirus identified) and the study group (rotavirus identified in the stools).

Results. Of the 169 babies screened for sepsis, 44 (26\%) were rotavirus positive. Of the remainder, 63 comprised the control group. Rotavirus-positive stools were identified from day 4 of life. The virus was excreted in the stools for a mean of 4 days per infection episode. Asymptomatic infection was only observed in one baby; the others had clinical signs and symptoms ranging from mild to severe, and there were even some deaths. Gastrointestinal symptoms were prominent manifestations of rotavirus infection. There was a high incidence of NEC (66\% in the study group v. 30\% in the control group). Of the rotavirus-infected babies, 9 died; 3 had no other pathogens identified, so that rotavirus infection could have been the cause of death.

Conclusions. Rotavirus infection in the neonate is rarely asymptomatic. It is a dangerous condition that may cause death. It is associated with, and probably a cause of, NEC.

S Afr Med J 2012;102(7):620-624.
Nearly 2 million children die from diarrhoeal disease every year worldwide; ${ }^{1}$ in South Africa, this disease causes the deaths of a quarter of children who die aged $1-5$ years. $^{2}$ Rotavirus infection is the most common cause of diarrhoeal disease in childhood and of considerable morbidity and mortality among infants and young children throughout the world. Most deaths from rotavirus occur in developing countries. ${ }^{1}$ Rotavirus infects all socio-economic groups and races, and essentially all children throughout the world have been infected by the virus by the age of 3 years. ${ }^{3}$ Rotavirus gastroenteritis causes an estimated 610000 deaths worldwide each year, and an increasing proportion of diarrhoeal disease is now due to rotavirus ( $40 \%$ cf. $25 \%){ }^{4}$

Unique strains of rotavirus occur endemically in neonates in neonatal and maternity units worldwide. Rotavirus infections in newborns are reported to be mild or asymptomatic, ${ }^{5}$ while infection with rotavirus during the neonatal period seems to protect the child clinically against severe gastroenteritis when re-infected later on in life. ${ }^{6}$

However, literature reports indicate that rotavirus could be associated with several other serious clinical conditions in infants: necrotising enterocolitis (NEC), ${ }^{7}$ pneumonia, sudden infant death syndrome, diffuse intravascular coagulopathy (DIC), ${ }^{8,9}$ seizures, ${ }^{9}$ encephalitis ${ }^{9}$ and episodes of bradycardia-apnoea. ${ }^{10}$

A neonatal death of an infant who died 18 hours postpartum with a clinical picture of DIC and afebrile convulsions, who had rotavirus infection, ${ }^{8}$ posed the question of whether the severity of neonatal rotavirus has been underestimated. Are we missing cases

Department of Paediatrics and Child Health, MEDUNSA Campus, University of Limpopo, Pretoria

François P R de Villiers, PhD, FCPaed, MMed, FACP

Marie Driessen, MB ChB, MSc where rotavirus plays a role in causing neonatal disease? We therefore studied the clinical signs and symptoms associated with rotavirus infection in our Neonatal Unit.

\section{Methods}

The study was conducted in the Neonatal Unit of Ga-Rankuwa Hospital, which admits babies $<4$ weeks old who need hospitalisation, including term and preterm newborns from labour wards at the hospital, and from local community clinics, rural referral hospitals and home deliveries. The disease profile included illnesses and anomalies expected in a tertiary care neonatal unit. Breast-feeding is promoted extensively; formula feeds are only occasionally used when breast-milk is contraindicated.

Newborns needing screening for suspected sepsis in the unit were studied. Screening for rotavirus was included whenever a septic screening was needed (rotavirus screening is not routinely included in the septic workup in this unit). Specimens collected for the septic workup were used, including blood, cerebrospinal fluid (CSF), throat swab, tracheal aspirates, colostomy or ileostomy fluid, and stools. If rotavirus was detected during such a septic workup, the baby was allocated to the rotavirus-positive study group. All clinical information since birth was retrospectively gathered, daily stool specimens were obtained henceforth, and available clinical data were recorded daily for the rest of the infant's hospital stay. Septic screen babies testing negatively for rotavirus were allocated to the control group, whose clinical information was obtained from retrieving a summary from the Neonatal Unit's computerised information system after the infant's discharge or death.

Laboratory studies were conducted at the departments of Microbiology and Virology of MEDUNSA and the MEDUNSA/ MRC Diarrhoeal Pathogens Research Unit. Stool samples were tested for rotavirus antigen, detected by a commercial enzyme-linked immunosorbent assay (ELISA) (Rotavirus IDEIA, Dako, Denmark).

The study was approved by the Research, Ethics, and Publications Committee of the Faculty of Medicine. Informed written consent was obtained from the mothers.

Data were statistically analysed using SAS. A confidence level of $5 \%$ was considered statistically significant. Descriptive statistics 
including mean, standard deviation, range and frequency tables were performed for each variable. Chi-square or Fisher's exact tests were done to test for associations between categorical variables. Student's $t$-test was performed to test for differences in means of continuous variables.

\section{Results}

Of the 169 babies who were screened for sepsis over a 14-month period, 44 were infected with rotavirus. Twelve babies were excluded whose stools tested weakly positive for rotavirus antigen but could not be confirmed. Of the remainder of the septic screen babies, only 63 summaries could be retrieved from the ward's computerised information system. Accordingly there were a rotavirus-positive study group $(n=44)$ and a rotavirus-negative control group ( $n=63)$.

There were no statistically significant differences between the study and control groups regarding their mass, gestational age, gender, booking status, presence of birth asphyxia (low 5-minute Apgar), presence of HIV antibodies, total days in hospital and mortality rate (Table 1). The study and control groups were therefore comparable. The age at which the first positive stool was found, and the period of rotavirus excretion in the study group, also appear in Table 1.

Table 2 shows the disease profile on admission for the babies in the different groups, reflecting the pathological problems that are encountered at our Neonatal Unit. Low birth weight $(<2500 \mathrm{~g})$ and respiratory distress were most frequent admission diagnoses for both groups. Neonatal sepsis occurred statistically more frequently in the control group than the rotavirus-positive study group.

The high incidence of rotavirus infection seems to indicate the endemic nature of rotavirus infection in this Neonatal Unit (Table 1); $44(28 \%)$ out of 157 babies were found to be infected with rotavirus during their hospital stay, of whom 4 contracted a second episode of rotavirus infection. Rotavirus was excreted for a mean of 4 days (range 1 - 15 days). The bigger and more term babies developed rotavirus

Table 1. Characteristics of infants studied

\begin{tabular}{|c|c|c|c|}
\hline & $\begin{array}{l}\mathrm{RV} \text { pos } \\
n=44\end{array}$ & $\begin{array}{l}\text { RV neg control } \\
n=63\end{array}$ & $p$-value \\
\hline \multicolumn{4}{|l|}{ Birth mass } \\
\hline Mean & 1659.3 & 1681.4 & 0.8199 \\
\hline Median & 1445 & 1460 & \\
\hline SD & 720.926 & 719.921 & \\
\hline Range & $720-3780$ & $900-1500$ & \\
\hline \multicolumn{4}{|l|}{ Gestational age (weeks) } \\
\hline Mean & 32.6 & 32.2 & 0.7396 \\
\hline Median & 32 & 32 & \\
\hline SD & 3.521 & 2.684 & \\
\hline Range & $24-40$ & $27-40$ & \\
\hline \multicolumn{4}{|l|}{ Gender } \\
\hline Female & $26(60.5 \%)$ & $37(59.7 \%)$ & 0.9357 \\
\hline Male & $17(39.5 \%)$ & $25(40.3 \%)$ & \\
\hline \multirow[t]{2}{*}{ No antenatal care } & $6(14 \%)$ & $17(26.9 \%)$ & 0.1100 \\
\hline & 1 unknown & & \\
\hline \multirow{2}{*}{ Low Apgar ( $<7$ at $5 \mathrm{~min}$.) } & $2(4.9 \%)$ & $6(9.5 \%)$ & 0.4443 \\
\hline & 3 unknown & 11 unknown & \\
\hline \multirow[t]{2}{*}{ HIV-positive antibodies } & $6(13.6 \%)$ & $14(27.5 \%)$ & 0.0996 \\
\hline & & 12 unknown & \\
\hline \multicolumn{4}{|l|}{ Age 1st pos stool } \\
\hline Mean & 21.3 & Not applicable & Not applicable \\
\hline Median & 19 & & \\
\hline SD & 11.894 & & \\
\hline Range & $4-46$ & & \\
\hline \multicolumn{4}{|l|}{ Days excreting } \\
\hline Mean & 4.3 & Not applicable & Not applicable \\
\hline Median & 2.5 & & \\
\hline SD & 4.135 & & \\
\hline Range & $1-15$ & & \\
\hline \multicolumn{4}{|l|}{ Total days in hospital } \\
\hline Mean & 37 & 36 & 0.8511 \\
\hline Median & 37.5 & 27 & \\
\hline SD & 15.987 & 32.6017 & \\
\hline Range & $10-74$ & $6-196$ & \\
\hline Mortality & $9(20.5 \%)$ & $16(25.4 \%)$ & 0.5522 \\
\hline
\end{tabular}


Table 2. Disease profile on admission

\begin{tabular}{|c|c|c|c|}
\hline & $\begin{array}{l}\text { RV pos } \\
n=44(\%)\end{array}$ & $\begin{array}{l}\text { RV neg } \\
n=63 \text { (\%) }\end{array}$ & $p$-value \\
\hline Low birth weight $<2500 \mathrm{~g}$ & $37(84.1)$ & $56(88.9)$ & 0.4710 \\
\hline Respiratory distress & $25(56.8)$ & $27(42.9)$ & 0.1570 \\
\hline Hyaline membrane disease & $9(20.5)$ & $23(36.5)$ & 0.0767 \\
\hline Meconium aspiration & $2(4.5)$ & $1(1.6)$ & 0.5670 \\
\hline Sepsis (unspecified) & $1(2.3)$ & $12(19)$ & 0.00896 \\
\hline Meningitis & 0 & $2(3.2)$ & 0.5112 \\
\hline Congenital syphilis & $2(4.5)$ & $6(9.5)$ & 0.4663 \\
\hline Birth asphyxia & $5(11.4)$ & $2(3.2)$ & 0.1211 \\
\hline Neonatal jaundice & $4(9.1)$ & $1(1.6)$ & 0.1568 \\
\hline Multiple pregnancy & $4(9.1)$ & $6(9.5)$ & 0.9399 \\
\hline Congenital abnormalities & $4(9.1)$ & $7(11.1)$ & 0.7361 \\
\hline Congenital heart defect & 0 & $1(1.6)$ & \\
\hline Hirschprung disease & 0 & $1(1.6)$ & \\
\hline Cleft palate & 0 & $1(1.6)$ & \\
\hline Tracheo-oesophageal fistula & $1(2.3)$ & 0 & \\
\hline Small bowel atresia & $1(2.3)$ & $1(1.6)$ & \\
\hline Omphalocoele/gastroschisis & 0 & $1(1.6)$ & \\
\hline Congenital rubella syndrome & $1(2.3)$ & 0 & \\
\hline Trisomy 21 (Down syndrome) & $1(2.3)$ & $1(1.6)$ & \\
\hline Trisomy 18 & 0 & $1(1.6)$ & \\
\hline
\end{tabular}

infection statistically significantly sooner than the smaller and more preterm babies ( $p=0.0001$; Spearman correlation coefficient).

To assess the signs and symptoms associated with neonatal rotavirus infection they should be compared with similar patients without rotavirus infection. In our study, the rotavirus-positive and -negative control groups were comparable. However, while the rotavirus-positive infants excreted rotavirus in their stools for a discrete time period, and their clinical signs and symptoms could be recorded, the control group patients were rotavirus-negative but had many other problems and complications that caused clinical signs and symptoms during their hospital stay, from admission to discharge. It was not feasible to select a time period during the control group's hospital stay which correlated with the same time period of rotavirus excretion for the study group, as both the age when the first rotavirus-positive stool was documented (4 - 46 days) and the duration of rotavirus excretion ( $1-15$ days) ranged widely. Noting this limitation of the study, Table 3 lists the clinical signs and symptoms in the two groups.

Rotavirus infection was not found to be asymptomatic in our patients. Apart from one baby in the study group (who only excreted rotavirus on the day before discharge) who was completely asymptomatic, all other rotavirus-infected babies had clinical signs and symptoms ranging from mild to severe, and there were even some deaths.

Signs and symptoms observed during the time of rotavirus infection were mainly general signs suggestive of sepsis in the neonate, including temperature instability especially pyrexia $\geq 38^{\circ} \mathrm{C}$, jaundice other than physiological, apnoea, respiratory deterioration, acidosis, anaemia, low platelet and white cell counts, and serum C-reactive protein. Pyrexia $>38^{\circ} \mathrm{C}$ was associated with rotavirus infection while, in the control group, sepsis was not associated with fever.

Gastrointestinal symptoms were prominent in the study group. Diarrhoea ( $\geq 6$ stools per day), vomiting, increased gastric aspirates, and bloody stools occurred much more frequently than in the control group. The modified Bell's staging criteria for NEC are used to diagnose NEC. Confirmed or suspected NEC was found in 28 (63.6\%) infants in the study, and 19 (30.2\%) infants in the control group. The difference was statistically significant $(p=0.001$, chisquare). This supports a possible link between rotavirus infection and NEC in the neonate.

Neither central nervous system (CNS)-related signs and symptoms nor respiratory symptoms were associated with rotavirus infection, as these symptoms also occurred in the control group; differences were not statistically significant. None of the throat swabs taken was positive for rotavirus when tested with the RT-PCT technique.

Positive blood cultures for other pathogens included species of Klebsiella, Pseudomonas, Candida, coagulase negative staphylococci, Staphylococcus aureus, Haemolytic streptococcus, Streptococcus group B and group D, and enteropathogenic Escherichia coli from stools. The most commonly associated pathogen was Klebsiella species: 4 infants had positive blood and/or stool cultures for Klebsiella. Positive stool cultures for stool pathogens were reported for 3 babies (Salmonella typhii and enteropathogenic E. coli in 2 infants). More babies in the rotavirus-negative control group (27.5\%) had antibodies for HIV than in the study group (13.6\%), although this difference was not statistically significant (Table 1).

Four babies had a second episode of rotavirus infection (after secreting negative stools for some time after the first infection); all had less severe symptoms with the second infection, except one who had mild symptoms in both episodes. This observation supports the literature in that infection induces clinical protection against the severity of re-infections, and that re-infections are common.

Nine $(20.5 \%)$ of the babies in the study group, and $16(25.4 \%)$ of the control group babies died (Table 1). Table 4 summarises the clinical picture and causes of the death for the rotavirus-infected babies. Of the 9 babies who died, 3 had no other pathogen identified, and it is possible that the rotavirus infection could have been the cause of death in these 3 babies. 
Table 3. Clinical signs and symptoms associated with rotavirus infection

\begin{tabular}{|c|c|c|c|}
\hline Signs and symptoms & $\begin{array}{l}\mathrm{RV} \text { pos } \\
n=44(\%)\end{array}$ & $\begin{array}{l}\text { RV neg control } \\
n=63(\%)\end{array}$ & $p$-value \\
\hline \multicolumn{4}{|l|}{ General } \\
\hline Asymptomatic & $1(2.3)$ & 0 & 0.4112 \\
\hline Unstable temperature & $11(25)$ & $5(7.9)$ & $0.0153^{*}$ \\
\hline Pyrexia $38^{\circ} \mathrm{C}$ & $22(50)$ & $2(3.2)$ & $0.00000^{*}$ \\
\hline Jaundice (other than physiological) & $4(9)$ & $5(7.9)$ & 0.8331 \\
\hline \multicolumn{4}{|l|}{ Gastrointestinal } \\
\hline Stools 6 or more per day & $16(36.4)$ & $5(7.9)$ & $0.00027^{*}$ \\
\hline Vomiting & $21(47.7)$ & $7(11.1)$ & $0.00002^{\star}$ \\
\hline Raised gastric aspirates & $26(59.0)$ & $18(28.6)$ & $0.00167^{*}$ \\
\hline Distended abdomen & $10(22.7)$ & $13(20.6)$ & 0.6059 \\
\hline Bloody stools & $15(34.0)$ & $4(6.3)$ & $0.00024^{*}$ \\
\hline Confirmed or suspected NEC & $28(63.6)$ & $19(30.2)$ & $0.00063^{*}$ \\
\hline \multicolumn{4}{|l|}{ Central nervous system } \\
\hline Apnoea & $11(25)$ & $16(25.4)$ & 0.9631 \\
\hline Jittery & $2(4.5)$ & $1(1.6)$ & 0.5671 \\
\hline Convulsions & 0 & $3(4.8)$ & 0.2628 \\
\hline Poor sucking & $2(4.5)$ & $1(1.6)$ & 0.5671 \\
\hline \multicolumn{4}{|l|}{ Respiratory tract } \\
\hline Mild respiratory distress & $3(6.8)$ & 0 & 0.0667 \\
\hline Needs oxygen headbox & $12(27.3)$ & $11(17.5)$ & 0.2262 \\
\hline Needs ventilation & $6(13.6)$ & $3(4.8)$ & 0.1565 \\
\hline \multicolumn{4}{|l|}{ Haematological abnormalities } \\
\hline Thrombocytopenia $\left(150 \times 10^{9} / \mathrm{l}\right)$ & $18(40.9)$ & $5(7.9)$ & $0.00005^{*}$ \\
\hline Anaemia & $24(54.5)$ & $25(39.7)$ & 0.1307 \\
\hline Leucopenia $\left(4 \times 10^{9} / 1\right)$ & $9(20.5)$ & Unknown & $\mathrm{n} / \mathrm{a}$ \\
\hline Raised C-reactive protein & $7(15.9)$ & Unknown & $\mathrm{n} / \mathrm{a}$ \\
\hline Diffuse intravascular coagulopathy & $3(6.8)$ & $4(6.3)$ & 0.9235 \\
\hline Positive cultures for other associated pathogens & $13(29.5)$ & $14(22.2)$ & 0.3930 \\
\hline \multirow[t]{2}{*}{ Stools pathogens positive ${ }^{*}$} & $3(7.3)$ & $2(5.0)$ & 0.6668 \\
\hline & (3 not done) & (23 not done) & \\
\hline
\end{tabular}

\section{Discussion}

The role of rotavirus as an important aetiological agent causing diarrhoea in young children and infants worldwide has long been established, as has the endemic presence of rotavirus causing mild or asymptomatic infections in neonatal nurseries worldwide. However, much remains to be learned about the epidemiology, transmission and pathophysiology of the virus. It is generally reported that rotavirus infection in neonates is either asymptomatic or mild, in contrast with infections in older children. ${ }^{7}$ In 1975, 2 years after Ruth Bishop discovered human rotaviruses, they were detected in the stools of symptom-free newborn babies in nurseries in several parts of the world. Bryden et al. ${ }^{11}$ described a sharp contrast between the asymptomatic or mild infections in neonates, and the severe diarrhoeal disease seen in older hospitalised children.

Rotavirus infection was found to be completely asymptomatic in only one baby in our study. All other infants had signs and symptoms. A limitation of our study is that the comparison of the signs and symptoms observed during rotavirus infection with those in the control group without rotavirus infection was not accurate, because the latter had many other problems and complications causing morbidity throughout their hospital stay. The control group might have been a sicker group of patients, with higher percentages of unbooked pregnancies, birth asphyxia (low 5-minute Apgar score), congenital syphilis, HIV-positive antibodies, and with a higher mortality, although none of these differences was statistically significant. These factors may imply that the statistical difference between the two groups might indeed have been more significant if we could have identified a truly comparable control group.

Signs and symptoms suggestive of sepsis were present in most of our infants with rotavirus infection. Chen et al. ${ }^{12}$ also reported this finding, that $57 \%$ of their rotavirus-positive neonates were symptomatic, with vomiting, poor feeding, elevated core temperature and diarrhoea. Kunz et al. ${ }^{13}$ studied all neonates in their premature baby ward and infant nursery, and reported pyrexia, vomiting, poor sucking, increased gastric residue, increased frequency of stool passage with a pathological quality (thready, green, mushy, stinking, slimy stools) and greyish skin colour, mottled skin, poor perfusion, and one infant with brief clonic convulsions. In our study, gastrointestinal symptoms were also prominent. As breast milk is used to feed our neonates, we used 6 stools per day as the cut-off point to determine increased frequency of stools passage. The quality of stools was not recorded. Other symptoms included vomiting, increased gastric aspirates before the next feed, and bloody stools.

Only fever, thrombocytopenia and gastrointestinal symptoms were associated with rotavirus infection in this study. In particular, there was no association with CNS signs and symptoms during the time of 
Table 4. Causes of death in rotavirus-infected babies

\begin{tabular}{|c|c|c|c|}
\hline Case number & Clinical picture & Causes of death & $\begin{array}{l}\text { Possibly related to } \\
\text { rotavirus }\end{array}$ \\
\hline 41 & Preterm, stage III B NEC, rotavirus the only pathogen & Respiratory failure & Yes \\
\hline 43 & $\begin{array}{l}\text { Preterm, bloody stools and vomiting (NEC), apnoea, } \\
\text { rotavirus the only pathogen }\end{array}$ & Respiratory failure & Yes \\
\hline 74 & $\begin{array}{l}\text { Preterm, had rotavirus infection which cleared up and } \\
\text { was discharged, re-admitted with sepsis }\end{array}$ & S. aureus meningitis & No \\
\hline 76 & $\begin{array}{l}\text { Preterm, apnoea, pneumonia, anaemia, distended } \\
\text { abdomen and brown gastric aspirates (NEC) }\end{array}$ & K. pneumoniae septicaemia & No \\
\hline 88 & $\begin{array}{l}\text { Preterm, respiratory deterioration, P24 Ag test pos, } \\
\text { frequent watery stools }\end{array}$ & $\begin{array}{l}\text { Possibly vomited and aspirated (milk was } \\
\text { sucked from airways) }\end{array}$ & Yes \\
\hline 96 & Preterm, apnoeic episodes, DIC & K. pneumoniae septicaemia & No \\
\hline 100 & $\begin{array}{l}\text { Preterm, bloody stools (NEC), developed chicken pox } 13 \\
\text { days after mother, apnoea, rotavirus-positive stools }\end{array}$ & Respiratory failure & Yes \\
\hline 102 & $\begin{array}{l}\text { Preterm, congenital rubella syndrome, neurologically } \\
\text { impaired, DIC, pyrexia, no other pathogen identified, } \\
\text { stools negative for rotavirus at time of death }\end{array}$ & Died on ventilator in decerebrate position & No \\
\hline 105 & Preterm, respiratory deterioration & Streptococcus group D meningitis & No \\
\hline
\end{tabular}

rotavirus infection in our rotavirus-positive patients; this finding has been reported in more detail, based on 2 studies. ${ }^{9}$

The pathogenesis of NEC is complex and multifactorial; there is no unique 'cause' of NEC. Neu ${ }^{14}$ summarised the risk factors associated with the development of NEC to be prematurity, aggressive enteral feeding, hypoxic-ischaemic insults, and infectious agents. Prematurity is reported to be the most important risk factor. In term and near-term infants, NEC may result from a specific ischaemic insult on the gastrointestinal tract. It has been suggested that NEC, at least in some cases, is a contagious disease. The evidence includes: epidemics of NEC, association of outbreaks with specific bacterial pathogens, interruption of epidemics by infection control measures, and prevention of NEC with oral antibiotics. Epidemics of NEC have been observed in most neonatal intensive care units. Pathogens implicated include E. coli, Klebsiella, Enterobacter, Pseudomonas, Salmonella, Clostridia, coronavirus, rotavirus and enteroviruses. Four babies from our study group had positive cultures for Klebsiella.

An important finding from our study was the large number of infants with confirmed or suspected NEC, who were also infected with rotavirus in our septic screen cohort: double the attack rate in our control group - a highly statistically significant difference $(p=0.00063)$. This observation supports the possible link between rotavirus infection and NEC in the neonate. Several investigators reported cases of NEC where rotavirus was the only pathogenic agent found. ${ }^{7}$ Of the 28 babies in our study who had suspected or confirmed NEC, 17 (60.7\%) had rotavirus as the only pathogenic agent identified. This result suggests that rotavirus should be included as an agent associated with NEC in the neonate.

The clinical picture and causes of death from our study for the 9 babies who died are summarised in Table 4 . No other pathogen was identified in 3 of these babies, and it is possible that these deaths could be rotavirus related. These babies were all preterm, and NEC was confirmed or suspected. The presence of rotavirus as the only infectious pathogen identified, strengthens the hypothesis that rotavirus should be listed as one of the infectious agents associated with NEC in the neonate.

\section{Conclusions}

Rotavirus infection seemed to be endemic in the Neonatal Unit of Ga-Rankuwa Hospital. Preterm and low birthweight neonates were infected at a later age than term and bigger neonates, and therefore seemed to be protected to some extent against rotavirus infection. Neonatal rotavirus infection was rarely asymptomatic in our neonatal population; more often, general signs and symptoms suggestive of sepsis were present to alert suspicion of infection.

Gastrointestinal signs and symptoms were the most prominently observed during rotavirus infection, with strong support for the possible link between NEC and rotavirus infections in neonates.

\section{References}

1. Waggie Z, Hawkridge A, Hussey GD. Review of rotavirus studies in Africa: 1976-2006. J Infect Dis 2010;202(S1):S23-33. [http://dx.doi.org/10.1086/653554]

2. MacIntyre UE, De Villiers FPR. The economic burden of diarreal disease in a tertiary level hospital, Gauteng, South Africa. J Infect Dis 2010;202(S1):S116-125. [http://dx.doi.org/10.1086/653560]

3. WHO. Rotavirus Vaccines: WHO Position Paper. Weekly Epid Rec 2007;82(32):285-296.

4. Parashar UD, Gibson CJ, Bresee JS, Glass RI. Rotavirus and severe childhood diarrhea. Emerg Infect Dis 2006;12(2):304-306.

Sharma R, Hudak ML, Premachandra BR, et al. Clinical manifestations of rotavirus infection in the neonatal intensive care unit. Pediatr Infect Dis J 2002;21:1099-1105. [http://dx.doi.org/10.1097/01. inf.0000040423.10649.bF]

6. Velazquez FR, Matson DO, Calva JJ, et al. Rotavirus infection in infants as protection against subsequent infections. N Engl J Med 1996;335:1022-1028. [http://dx.doi.org/10.1056/NEJM 199610033351404] 7. Sharma R, Garrison RD, Tepas JJ, et al. Rotavirus-associated necrotizing enterocolitis: an insight into . Sharma R, Garrison RD, Tepas JJ, et al. Rotavirus-associated necrotizing enterocolitis: an insight into
a potentially preventable disease? J Pediatr Surg 2004;39(3):453-457 [http://dx.doi.org/10.1016/j. a potentially preventable disease? J Pediatr Surg 2004;39(3):453-457 [http://dx.doi.org/10.1016/].
pedsurg.2003.11.016] pedsurg.2003.11.016]

8. Pager C, Steele AD, Gwamanda P, Driessen M. A neonatal death associated with rotavirus infection detection of rotavirus ds RNA in the cerebrospinal fluid. S Afr Med J 2000;90(4):364-365.

9. De Villiers FPR, Steele AD, Driessen M. Cental nervous system involvement in neonatal rotavirus infection. Ann Trop Paediatr 2003;23:309-312 [http://dx.doi.org/10.1179/027249303225 007789]

10. Huppertz H-I, Salman N, Giaquinto C. Risk factors for severe rotavirus gastroenteritis. Pediatr Infect Dis J 2008;27:S11-19 [http://dx.doi.org/10.1097/INF.06013e31815eeeO9]

11. Bryden AS, Thouless ME, Hall CJ, et al. Rotavirus infections in a special-care baby unit. J Infect 1982;4:43-48 [http://dx.doi.org/10.1016/SO163-4453(82)90988-4]

12. Chen HN, Dennehy PH, Oh W, Lee CN, Huang ML, Tsao LY. Outbreak and control of a rotaviral infection in a nursery. J Formos Med Assoc 1997;96(11):884-889.

13. Kunz J, Slongo R, Schams M, Zbinden R. An outbreak of rotavirus infections in newborns - new aspects? J Perinat Med 1990;18:357-362 [http://dx.doi.org/10.1515/jpme.1990.18.5.357]
and

14. Neu J. Necrotizing enterocolitis: the search for a unifying pathogenic theory leading to prevention. Pediatr Clin North Am 1996;43(2):409-432. 